\title{
MEMÓRIA DISCURSIVA: A RESSIGNIFICAÇÃO DOS DITADOS POPULARES EM LETRAS DE MÚSICA BRASILEIRAS COMO FORMA DE CRITICAR OS SUJEITOS EM SEUS DIFERENTES PAPÉIS SOCIAIS
}

\author{
FRANCISCO ALVES FILHO ${ }^{1}$ \\ LAFITY DOS SANTOS ALVES ${ }^{2}$
}

\begin{abstract}
Programa de Pós-Graduação em Letras (PPGEL)
Centro de Ciências Humanas e Letras - CCHL

Universidade Federal do Piauí - UFPI, Campus Universitário Ministro Petrônio Portella. Bairro Ininga - Teresina - PI - CEP: 64049-550
\end{abstract}

chicofilhoo@ufpi.edu.br, lacf2806@gmail.com

\begin{abstract}
Resumo. $O$ discurso é o resultado de um jogo de efeitos de sentido em que diferentes posições de sujeito dialogam, tecendo um novo discurso inscrito histórica, social e ideologicamente. Quando estamos diante de um novo acontecimento, fazemos uso de algo que já foi dito em um dado momento e lugar. Porém, o sujeito-enunciador ressignifica essa forma de dizer para tomar aquele discurso, que é coletivo, como sendo algo de caráter individual. Ao fazer isso, assumem como propósito, em seus discursos, criticar o comportamento dos sujeitos em seus diferentes papéis sociais. Por isso, o sujeito se sente a fonte de um dizer que é social e histórico. Diante disso, este trabalho tem como objetivo analisar o funcionamento da memória discursiva em letras de música brasileiras que fazem uso de ditados populares. Para isso, fizemos uso, principalmente, das teorias discursivas sobre discurso e memória discursiva de Pêcheux (1988; 2010) e Orlandi (2007).
\end{abstract}

Palavras-chave: Discurso; Ditados populares; Memória discursiva; Letras de música.

\begin{abstract}
The discourse is the result of a game of effects of meaning in which different positions of subject dialogue, weaving a new discourse inscribed historically, socially and ideologically. When we are facing a new event, we make use of something that has already been said at a given time and place. However, the subject-enunciator resignifies this way of saying to take that discourse, which is collective, as something of an individual character. And its purpose is to criticize the behavior of the subjects in their different social roles. Therefore, the subject feels the source of a saying that is social and historical. Therefore, this work aims to analyze the functioning of discursive memory in Brazilian lyrics that use proverbs. For this, we used mainly the
\end{abstract}

\footnotetext{
${ }^{1}$ Professor do Programa de Pós-Graduação em Letras da UFPI. Doutor em Linguística pela UNICAMP.

${ }^{2}$ Doutoranda em Linguística (PPGEL-UFPI). Mestre em Linguística (PPGEL-UFPI). Professora de Análise Linguística (Instituto Dom Barreto-IDB).
} 
discursive theories on discourse and discursive memory by Pêcheux (1988; 2010) and Orlandi (2007).

Keywords: Discourse; Proverbs; Discursive memory; Lyrics.

\section{INTRODUÇÃO}

A memória discursiva é uma terminologia da Análise de Discurso (AD) que marca a presença de diversos discursos históricos e sociais que circulam em uma dada sociedade. E o entrecruzamento desses discursos se dá por meio da formação discursiva, por isso os enunciados proferidos por nós, em dado contexto, são carregados de valores ideológicos. E é assim que a relação interdiscursiva dos enunciados, que circulam na sociedade, contribui para a constituição de um determinado discurso.

A memória discursiva "diz respeito à existência histórica do enunciado no seio de práticas discursivas reguladas pelos aparelhos ideológicos" (INDURSKY, 2011, p. 86). Desse modo, podemos afirmar que tanto o interdiscurso como a memória discursiva são relevantes na/para a constituição do discurso dos ditados utilizados em letras de música, corpus de análise dessa pesquisa.

Nessa perspectiva, esse estudo tem como objetivo analisar o funcionamento da memória discursiva dos ditados populares utilizados em letras de música brasileiras. Para tanto, fundamentamo-nos, principalmente, nos pressupostos teóricos de Pêcheux (1988; 2010) e Orlandi (2012), para os quais a memória discursiva se mostra como uma forma significativa na formação discursiva. Visto dessa maneira, o discurso é o resultado de um jogo de efeitos de sentidos em que diferentes posições de sujeito dialogam, tecendo um novo discurso inscrito histórica, social e ideologicamente.

Nesse sentido, analisamos as marcas linguísticas que demarcam a repetição, a paráfrase, bem como dizeres (que circulam socialmente) em quatro letras de música brasileiras (nas quais os enunciadores resgatam um acontecimento histórico através de ditados populares para criticar um comportamento social dos sujeitos - no exercício dos seus diferentes papéis sociais).

\section{DISCURSO E INTERDISCURSO}

Pêcheux (1988) concebe o discurso como o efeito de sentidos entre os locutores e, por isso, não pode ser visto tão somente como um processo de transmissão de informações, pois, no processo de interação, de interlocução, os sujeitos se constituem. Assim,

\footnotetext{
A Análise de Discurso, como seu próprio nome indica, não trata da língua, não trata da gramática, embora todas essas coisas lhe interessem. Ela trata do discurso. E a palavra discurso, etimologicamente, tem em si a ideia de curso, de percurso, de correr por, de movimento. O discurso é assim palavra em movimento, prática de linguagem: com o estudo do discurso observa-se o homem falando (ORLANDI, 2007, p. 15).
} 
Visto dessa maneira, o discurso é histórico, é ideológico, já que é produzido socialmente, culturalmente. Por isso, o discurso tem uma memória, já que nasce de outro discurso pelo processo de repetição ou de modificação. O discurso, então, é histórico, é a história marcada em nossa língua. Assim, a tríade sujeito, história e língua marcam a constituição discursiva. Portanto, o discurso se estabelece por meio dos mecanismos de produção de sentidos nos processos de comunicação diversos.

Mazière (2007) também defende a ideia de que o discurso não é de caráter individual, porque falar de discurso implica "vermos" o não dito, o não visível no processo de comunicação entre os sujeitos. Isso porque, segundo Brasil (2011, p. 181), "o discurso é o efeito de sentidos entre sujeitos interpelados pela ideologia, chamados por dizeres não apreensíveis no engano da obviedade".

Martín-Barbero (1978) também relaciona a noção de discurso à de história, pois o autor vê o discurso como uma prática atravessada por outros discursos, mas também como uma prática social e histórica. Essa ideia lembra a noção de interdiscurso defendida por Orlandi (1999), pois a autora define essa terminologia como aquilo que fala antes, de outro lugar. Desse modo, o interdiscurso tem relação com outro discurso já proferido historicamente.

O interdiscurso apresenta uma relação intrínseca com a memória discursiva, uma vez que a memória faz parte do discurso.

\section{MEMÓRIA DISCURSIVA}

A terminologia memória discursiva, do ponto de vista de Pêcheux (2010), faz referência aos dizeres utilizados recorrentemente pelos sujeitos em um dado momento da história. Esses dizeres podem ser atualizados ou esquecidos nos mais diferentes processos de comunicação. Ao fazermos uso do discurso, falamos de algo anterior. Assim, no processo de comunicação, fazemos uso de dizeres que falam de outro lugar, que falam antes.

Concebida dessa maneira, a memória discursiva não é algo que se constrói individualmente. Não se trata de uma lembrança pessoal. A memória decorre do coletivo, pois é através do social que surgem as condições para o funcionamento discursivo. Por isso, Pêcheux (2010) defende a ideia de que os sentidos são construídos a partir das práticas inscritas socialmente, culturalmente e historicamente. Dessa forma,

A memória seria aquilo que, face a um texto que surge como acontecimento a ler, vem restabelecer os implícitos (quer dizer, mais tecnicamente, os pré-construídos, elementos citados e relatados, discursos-transversos, etc.) de que sua leitura necessita: a condição do legível em relação ao próprio legível (PÊCHEUX, 2010, p. 52).

Diante disso, é a memória discursiva que nos possibilita retomar os discursos já ditos em outro momento, em uma dada circunstância social, história e cultural, em uma situação discursiva atualizada. Com isso, a memória funciona como uma espécie de retomada de discursos já utilizados em outros acontecimentos anteriores. Para o 
pesquisador, a memória serve como uma forma de sustentação das forças ideológicas que apresentam como propósito a retomada dos pré-construídos. Porém, o autor concebe a existência de uma força antagônica capaz de desestabilizar, de desregular os discursos já ditos. Assim, nas palavras do próprio pesquisador: "há sempre um jogo de força na memória sob o choque do acontecimento" (PÊCHEUX, 2010, p. 53). Dito de outra maneira: o acontecimento discursivo novo pode regular, estabilizar a rede dos já ditos, porém, esse novo acontecimento também pode deslocar, desestabilizar a memória. A desestabilização da memória resulta da opacidade do não dito, dos implícitos. Visto dessa maneira,

... uma memória não poderia ser concebida como uma esfera plena, cujas bordas seriam transcendentais históricos e cujo conteúdo seria um sentido homogêneo, acumulado ao modo de um reservatório: é necessariamente um espaço móvel de divisões, de disjunções, de deslocamentos e de retomadas, de conflitos de regularização... Um espaço de desdobramentos, réplicas, polêmicas e contradiscursos (PÊCHEUX, 2010, p. 56).

A memória funciona de forma flexível, uma vez que permite a repetição de discursos pré-construídos, já ditos, mas pode transfigurar, se transformar diante de um novo acontecimento discursivo. Diante de um acontecimento novo, a memória se transfigura em novas, atualizadas paráfrases.

\section{DITOS POPULARES}

Os ditados populares são construções curtas com o propósito de fazer uma advertência ou de aconselhar alguém em uma dada situação comunicativa. Além disso, os ditados caracterizam-se por se estenderem a variadas gerações em diferentes momentos da história. Eles representam um conhecimento popular, uma vez que constituem a cultura de um dado povo.

Os sentidos são construídos ao longo da história. Assim, os ditos populares não pertencem a um indivíduo, uma vez que eles fazem parte de uma coletividade, da história de um povo. A visão discursiva dos ditos populares no processo de comunicação aponta para a ideia de que são os sujeitos os produtores de um dizer, pois eles pressupõem produzir, do ponto de vista de Coracini e Pereira (2001), sentidos, uma vez que se identificam com aquilo que anunciam numa dada situação comunicativa.

Silva (2008) defende a existência de um processo polifônico entre o enunciado "Tal filha, tal mãe" e o ditado "Tal pai, tal filho". Afirma ainda que o enunciador dá um caráter de implicitude à origem (fonte) de seu enunciado, uma vez que deixa a encargo do coenunciador a tarefa de identificar o dizer do enunciador como parte de um conhecimento cultural de um povo. Por isso, afirma a autora, podemos afirmar que o enunciador retomou a fala de um outro, uma vez que utilizou a voz da sabedoria popular em seu discurso. Para isso, utilizou-se de um conhecimento coletivo. E para compreender o sentido do ditado, o coenunciador, também, fará uso da memória discursiva. Portanto, cabe tanto ao sujeito-enunciador quanto ao sujeito-leitor recorrer à memória discursiva para reforçar o discurso. 
Ainda sobre o ditado "Tal pai, tal filho", divulgado e aceito socialmente e culturalmente, Silva (2008) advoga que há um não-dito demarcado na repetição do operador "tal... tal...". E essa repetição aponta para o significado de que assim como é o pai, é o filho.

Alvarez (2004), pautando-se nos pressupostos de Foucault (1996), advoga que:

A vontade de verdade que atravessou séculos na história dos ditos populares cria a separação que rege nossa vontade de saber, saber que os exclui e os retoma de diferentes formas, repetindo o já-conhecido e instaurando o novo, que não está no que é dito, mas no acontecimento de sua volta (ALVAREZ, 2004, p. 5).

A autora defende que os sujeitos constroem, a partir do que já é de conhecimento coletivo da sociedade, um discurso repetido, que faz parte do acontecimento à sua volta.

\section{O JÁ DITO: DITADOS POPULARES EM LETRAS DE MÚSICA BRASILEIRAS}

Os sentidos são construídos de acordo com o condicionamento dos discursos na história e na língua de um povo. Por isso, os sujeitos trazem em seus discursos algo do que se falou antes (em outro momento, em outro espaço), o que faz parte de um conhecimento social, coletivo. Esse conhecimento coletivo é o que Pêcheux (2010) chama de interdiscurso. Orlandi (2007), assim como Pêcheux (2010), determina o interdiscurso como as formulações esquecidas e que determinam o nosso dizer. Esse dizer faz parte de um conhecimento social e histórico, porque está no domínio da memória discursiva.

Os ditos populares em letras de música pressupõem sujeitos que produzem o dizer. Desse modo, a letra de música "Cada macaco em seu galho", na composição de Clementino Rodrigues, cantada por cantores como Gilberto Gil e Caetano Veloso, faz com que o sujeito-enunciador pareça ser a fonte/origem do ditado popular. Porém, essa expressão popular (que significa que cada um de nós devemos nos preocupar somente com aquilo que nos diz respeito, por isso devemos reconhecer o nosso lugar e não nos metermos em assuntos alheios) não é algo novo, o sujeito fez uso da sua memória discursiva para retomar esse significado na letra de música para traduzir o anseio de liberdade do povo durante o período da ditadura militar no Brasil. Analisemos o trecho a seguir:

Xô xuá

Eu não me canso de falar

Xô xuá

O meu galho é na Bahia

Xô xuá

O seu é em outro lugar

Xô xuá

Embora o compositor ressignifique o ditado, esse dizer não é novo, uma vez que tanto o sujeito-enunciador quanto o sujeito-leitor compartilham de um conhecimento de 
mundo que circula socialmente e culturalmente em diferentes momentos da nossa história. Portanto, o dizer, marcado na composição, é um já dito em outro momento, em outro lugar. Esse dizer reativa representações culturalmente construídas na memória discursiva dos sujeitos. Desse modo, podemos afirmar que a memória está associada à existência histórica do enunciado nas diferentes práticas discursivas. No caso da composição analisada, o discurso funciona como uma forma de ressignificar saberes através de dizeres retomados e acionados através da memória. No caso do ditado presente na música, a memória discursiva é reconstruída em um novo discurso. E isso faz com que o discurso produzido seja um objeto de retomada que faz a memória ser evidenciada.

Quando o sujeito-enunciador faz uso das construções, como: "Eu não me canso de falar", "O meu galho é na Bahia" e "O seu é em outro lugar", percebemos uma evidência do passado memorizado que foi reformulado no novo acontecimento.

A letra de música “Aos filhos de Peixes”, de composição de Oswaldo Montenegro, da mesma forma que na letra de música "Cada macaco no seu galho", traz um dizer de um passado também memorizado de forma a ressignificar o ditado "Filho de peixe, peixinho é". Vejamos este trecho:

É peixe quando pula e descortina

A clara possibilidade de mudar de opinião

É peixe quando sem ligar a seta muda o rumo

Inverte a coisa, embola o pensamento e então

Na composição, vemos uma reformulação do ditado em um novo acontecimento, uma vez que a ideia de que normalmente as pessoas seguem os passos dos seus pais, principalmente, quando se trata de escolhas e comportamento, foi transfigurada. Dito de outra maneira: o filho de peixe pode ter uma opinião, um comportamento diferente daquela defendida pelo pai. O filho de peixe pode ser diferente, pode tomar rumos diferentes daqueles que foram tomados pelo pai. Portanto, há, na composição, um dizer de outros já ditos de modo a produzir novos sentidos em relação à memória discursiva. Assim, nas palavras de Pêcheux (2010, p. 56): a memória "é necessariamente um espaço móvel de divisões, de disjunções, de deslocamentos e de retomadas, de conflitos de regularização... Um espaço de desdobramentos, réplicas, polêmicas e contra-discursos".

Os ditados analisados até aqui representam um acontecimento único, um fato determinado no tempo e no espaço. No entanto, o novo dizer nada mais é do que uma representação de um já dito anteriormente, como podemos ver no trecho a seguir:

Meu coração não é casa da mãe Joana

Pra você bagunçar igual 'cê faz na minha cama

Respeita quem te ama

'Cê acha que me ilude

O trecho da letra de música acima, de composição de Elcio Di Carvalho, Thales Lessa e Victor Hugo também representa algo que já foi dito por outro sujeito em outro momento da história. Portanto, embora, ressignificado, esse dizer não é novo, uma vez que ele não é da ordem do individual, mas de uma coletividade. O ditado "casa da mãe Joana" foi utilizado para representar o comportamento desrespeitoso das pessoas nas 
relações conjugais. A evidência dessa desordem é marcada através da memória discursiva que foi reconstruída/retomada em um novo discurso. Portanto, o discurso decorre da materialidade linguística significante e a história.

Visto dessa maneira, concordamos com Orlandi (1995, p. 35), quando a autora defende a ideia de que "a significância não se estabelece na indiferença dos materiais que se constituem, ao contrário, é na prática material significante que os sentidos se atualizam, ganham corpo, significando particularmente". Ou seja, os discursos apresentam sentidos específicos de acordo com a materialidade significante que os constituem. Medrado:

Vejamos este trecho de uma outra letra de música, de composição de $\mathrm{MC}$

Fala mal de mim, ela quer ser eu

Acho que desse detalhe ela esqueceu (é)

Ta na frente do espelho, passando batom

Olhando as minhas fotos pra ficar no mesmo tom

Arruma os cachos no cabelo, fazendo babyliss

Ela olha a minha bonda e pede bis

Ela é minha fã, mas ela não que assumir (não quer)

Fala que me odeia, quer me substituir

(...)

Mais uma vez, vemos que o sujeito faz uma retomada da fala de um outro, uma vez que a voz que enuncia é a da sabedoria popular. O enunciador usa da memória discursiva para interpretar o comportamento da mulher diante das outras. É nessa perspectiva que visualizamos o discurso sendo deslocado, retomado através da memória discursiva do sujeito-enunciador. Como o conhecimento popular é algo coletivo, o sujeito-leitor, também, reconhecerá facilmente o conhecimento de mundo transmitido na letra de música, pois se identificará com os sentidos ali produzidos.

\section{CONSIDERAÇÕES FINAIS}

A análise dos ditados em letras de música brasileiras nos permite dizer que a memória é um fato social, pois ela constitui os discursos através do mecanismo de retomada, de réplicas. Ou seja, o passado se evidencia no discurso das músicas a partir de reformulações de dizeres já pronunciados em outro momento. Porém, o enunciador, por estar em um novo acontecimento, acredita ser ele a fonte, a origem do dizer.

Os ditados são marcados pela historicidade que é constitutiva do discurso. Portanto, os ditados envolvem efeitos de sentido que não resultam somente daquilo que vimos ou ouvimos. Partem de dizeres ressignificados em novos acontecimentos discursivos. Por isso, os discursos demarcados pelos ditos populares, nas letras de música, produzem sentidos que vão além da literalidade do que se vê, do que se ouve.

Portanto, nos ditados utilizados nas letras de música, resgata-se um acontecimento histórico que se faz materializar de forma ressignificada. E isso nos possibilita enxergar que tanto a memória discursiva quanto o interdiscurso são percebidos através de marcas 
linguísticas que demarcam a repetição, a paráfrase, bem como dizeres que circulam socialmente.

\section{REFERÊNCIAS}

ALVAREZ, S. M. Os ditos populares e sua utilização na mídia. Estudos Linguísticos XXXIII, p. 1060-1065, 2004. [ 1060 / 1065 ]

BRASIL, L. L. Michel Pêcheux e a teoria da Análise de Discurso: desdobramentos importantes para a compreensão de uma tipologia discursiva. Linguagem - Estudos e Pesquisas. V.15, n.1, p. 171-182, jan/jun, 2011.

CORACINI, M.J; PEREIRA. A E. Discurso e Sociedade Práticas em Análise do Discurso. Pelotas: Educat, 2001, p.137-155.

DI CARVALHO, E.; LESSA, T.; HUGO, V. Casa da mãe Joana. Disponível em: https://www.letras.mus.br/marilia-mendonca/casa-da-mae-joana-part-henrique-ejuliano/. Acesso em: 02 de setembro de 2020, às 14h $15 \mathrm{~min}$.

FOUCAULT, M. A ordem do discurso. São Paulo: Edições Loyola, 1996.

INDURSKY, F. A memória na cena do discurso. In: INDURSKY, F; MITTMAN, S; FERREIRA, M.C.L. Memória e história na/da análise do discurso. Campinas, SP: Mercado de Letras, 2011, p. 67-89.

MARTÍN-BARBERO, J. Comunicación masiva: discurso y poder. Quito: Editora Época, 1978.

MAZIÈRE, F. A Análise do Discurso: História e Práticas. São Paulo: Parábola, 2007.

MEDRADO, MC. Cachorro que late não morde. Disponível em: https://www.letras.mus.br/mc-medrado/cachorro-que-late-nao-morde/. Acesso em: 02 de setembro de 2020, às $14 \mathrm{~h} 34 \mathrm{~min}$.

MONTENEGRO, O. Aos filhos de peixes. Disponível em: https://www.letras.mus.br/oswaldo-montenegro/82833/. Acesso em: 02 de setembro de 2020 , às $14 \mathrm{~h} 20 \mathrm{~min}$.

SILVA, O. S. F. Os ditos e os não-ditos do discurso: movimentos de sentidos por entre os implícitos da linguagem. R. Faced, Salvador, n.14, p.39-53, jul./dez. 2008.

ORLANDI, E. Análise de Discurso: princípios e procedimentos. Campinas: Pontes, 2007.

PÊCHEUX, M. Semântica e discurso. Campinas: Pontes, 1988.

PÊCHEUX, M. O papel da memória. In: ACHARD, P. et al. O papel da memória. Tradução de José Horta Nunes. 3. ed. Campinas: Pontes, 2010.

RODRIGUES, C. Cada macaco no seu galho. Disponível em: https://www.letras.mus.br/riachao/cada-macaco-no-seu-galho/. Acesso em: $02 \mathrm{de}$ setembro de 2020 , às $14 \mathrm{~h}$.

Artigo recebido em: mar. de 2020.

Aprovado e revisado em: out. de 2020.

Publicado em: dez. de 2020.

Para citar este texto: 
ALVES FILHO, Francisco; ALVES, Lafity dos Santos. Memória Discursiva: a ressignificação dos ditados populares em letras de música brasileiras como forma de criticar os sujeitos em seus diferentes papéis sociais. Entremeios [Revista de Estudos do Discurso, ISSN 2179-3514, on-line, www.entremeios.inf.br], Seção Temática, Programa de Pós-Graduação em Ciências da Linguagem (PPGCL), Universidade do Vale do Sapucaí (UNIVÁS), Pouso Alegre (MG), vol. 22, p. 255-263, jul. - dez. 2020.

DOI: http://dx.doi.org/10.20337/ISSN2179-3514revistaENTREMEIOSvol22pagina255a263 